\title{
A Pathoplastic Presentation of Trichotillomania in Severe Depression- A Case Report
}

\author{
Malalagama $\mathbf{A S}^{*}$ \\ Consultant Psychiatrist, Base Hospital Warakapola, Ministry of Health, Sri Lanka \\ "Corresponding Author: Dr. Malalagama AS, Consultant Psychiatrist, Ministry of Health, Sri Lanka, Tel: \\ +94714400627; E-mail: shakunthini@yahoo.com
}

Received: 30 July 2018; Accepted: 15 August 2018; Published: 20 August 2018

\section{Introduction}

Recurrent failure to resist impulses to pull out hairs, a condition known as Trichotillomania is categorized under Habit and Impulse disorders in ICD-10 [1]. It causes a significant hair loss and psychosocial impairment and is associated with psychiatric comorbidity, mainly mood and anxiety disorders. A clinical sample within a treatment study reported common co-occurrence of major depression (28.6\%) and Obsessive Compulsive Disorder (10.7\%) [2]. Prevalence is between $0.6 \%$ and $3.6 \%$ in adults [3]. It is generally more common in women than in men, but there are some discrepancies. Most research has shown that the gender ratio is skewed toward females at a 9:1 ratio [4], but other studies have shown little or no gender differences [5, 6]. Usual onset is around 13yrs of age [7]. Trichotillomania most often results in secondary depression due to associated thoughts of low self-esteem, social isolation and embarrassment due to cosmetic effects and functional impairment. It can present as an independent entity ("Primary Trichotillomania") or as a syndrome accompanying and directly related to another disorder such as an affective disorder or an organic brain disease ("Secondary Trichotillomania) [8]. This case report is on a patient who presented with severe depression and manifested a severe degree of hair pulling during the episode, where clinical features mimicked an episode of Trichotillomania. This is the first case report of this nature in Sri Lanka.

Keywords: Trichotillomania; Depression; Pathoplastic presentation; Comorbidity

\section{Case Report}

A $53 \mathrm{yr}$ old man was admitted to the surgical ward for management of prolapsed haemorrhoides. He was referred to the psychiatry unit due to reduced speaking, eating and poor sleep. On assessment he had psychomotor retardation, almost mute and severely depressed. Beck Depression Inventory (BDI) score was 53 on admission. Hair in the entire 
frontal and half of bilateral parietal and temporal regions were absent with a clear margin (Figure 1). There were short strands of hair growing. No dermatological lesions were found. On questioning he revealed that he pulled his hair out as he felt compelled to and felt a discomfort in the scalp. He had thrown away the hair strands. He denied any psychotic belief related to hair pulling and felt relieved after pulling hair out. There were no psychotic symptoms. He denied feeling distressed due to the hair loss or was not worried about the appearance. The hair pulling has started one month back and got worse with time. He was pulling his hair when alone. Family revealed that he was depressed for the last 4 months and tried to leave home several times and became agitated when tried to stop. They couldn't bring him to hospital due to his resistance. But when he had prolapsed haemorrhoids, the pain made him seek medical help.

He has a history of severe depression, 17 yrs back, when he was treated with electroconvulsive therapy (ECT). A second relapse occurred 2 yrs later after he defaulted treatment. He was well without medication for the next 10 yrs until this relapse. He had been dysthymic for the past 3 yrs following his mother's death and gradually became depressed during the past 4 months. He has not shown the hair pulling behaviours in the past episodes, but has had psychotic symptoms. These is no family history of psychiatric illnesses or suicides or a past medical/dermatological history. He was treated with imipramine $150 \mathrm{mg}$ nocte, olanzapine $10 \mathrm{mg}$ mane, $20 \mathrm{mg}$ nocte and was given 6 ECTs. He improved in mood and behaviour. BDI score came down to 12. Hair started growing again. He no longer had a desire to pull out hair (Figure 2).

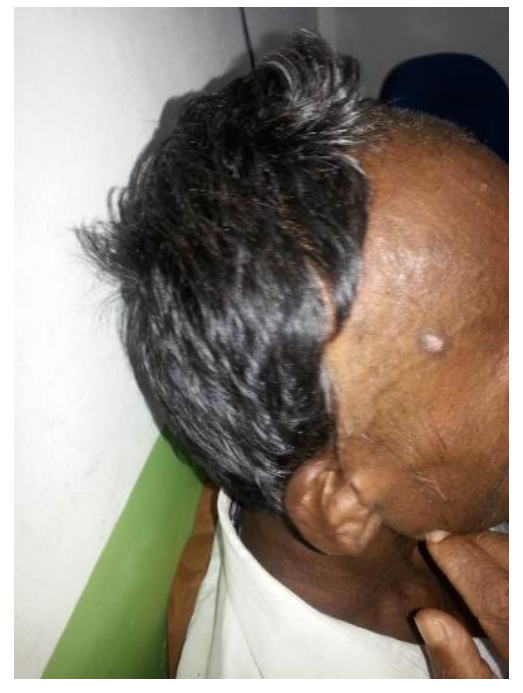

Figure 1: Before treatment.

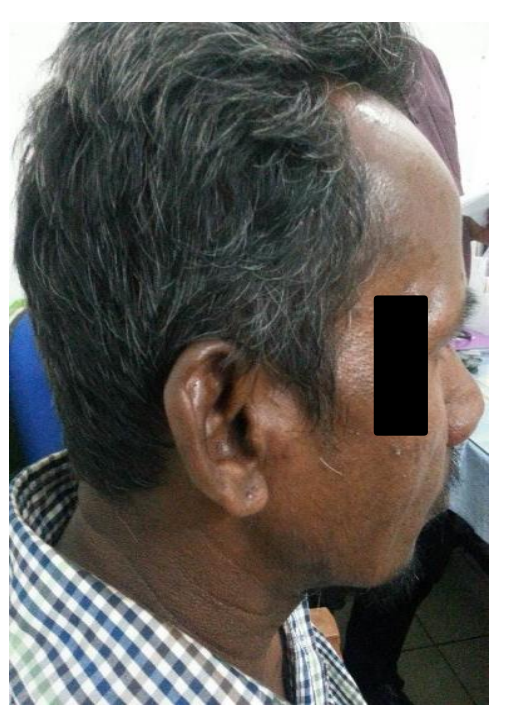

Figure 2: After treatment.

\section{Discussion}

The patient has had two previous depressive episodes leading to a diagnosis of Recurrent Depressive Disorder. Hair pulling started 3 months after the onset of current depressive symptoms. This exhibits the chronological relationship of the two conditions. The current episode fulfils criteria for severe depression according to ICD-10. His hair pulling habit is compatible with Trichotillomania according to ICD-10 criteria which is "a disorder characterized by noticeable hair loss due to a recurrent failure to resist impulses to pull out hairs. The hair-pulling is usually preceded by mounting tension and is followed by a sense of relief or gratification. This diagnosis should not be made if there 
is a pre-existing inflammation of the skin, or if the hair-pulling is in response to a delusion or a hallucination" [1]. But according to DSM-V, Trichotillomania cannot be diagnosed if the symptoms are better accounted for by another mental disorder [9]. In this case, hair pulling was present during the episode of severe depression, which would have been driven by different types of negative affect, such as high negative arousal (e.g., stress) and insufficient levels of arousal (e.g., boredom) [4]. In Trichotillomania, hair pulling can be performed in response to negative affect, leading to emotional relief in the short term at the expense of strengthening the act of pulling in the long term. Therefore according to DSM-V, Trichotillomania cannot be diagnosed in this patient and is likely to be secondary to severe depression. It is further confirmed by the fact that the symptoms improved when mood improved with treatment. Even though it can be argued that the antidepressant used to treat depression also treated Trichotillomania, it is known that Trichotillomania is a pervasive and a chronic disorder that takes a long time to respond to treatment. But in this patient, hair pulling improved within a week of treatment. It is more likely that improvement of depression brought about improvement of compulsion to pull hair. Also, primary Trichotillomania classically starts in childhood and adolescence, whereas this patient had the onset of hair pulling at the age of 53 yrs.

\section{Conclusions}

It can be deduced from this case that Trichotillomania can present as a Pathoplastic presentation (the ability of a disorder in mimicking clinical features of another known disorder) rather than as a comorbidity to another disorder.

There are cases reported where Trichotillomania has presented as a Pathoplastic condition with Bipolar affective disorder and Vascular dementia $[8,10]$. This case also brings light to the important differences between ICD-10 and DSM-V criteria for Trichotillomania.

\section{References}

1. World Health Organization. The ICD-10 classification of mental and behavioural disorders: clinical descriptions and diagnostic guidelines. Geneva (1992).

2. Woods DW, Wetterneck CT, Flessner CA. A controlled evaluation of acceptance and commitment therapy plus habit reversal as a treatment for trichotillomania. Behav Res Ther 44 (2006): 639-656.

3. Christienson GA, Pyle RL, Mitchell JE. Estimate lifetime prevalence of trichotillomania in college students. J Clin Psychiatry 52 (1991): 415-417.

4. Christenson GA. Trichotillomania: from prevalence to comorbidity. Psychiatr Times 12 (1995): 44-48.

5. Reeve E. Hair pulling in children and adolescents. In: Stein DJ, Christenson GA, Hollander E. Trichotillomania. Washington DC: American Psychiatric Press (1999): 201-224.

6. Duke DC, Bozdin DK, Tavares P. The phenomenology of hair pulling in a community sample. J Anxiety Disord 23 (2009): 1118-1125.

7. Christenson GA, Mackenzie TB, Mitchell JE. Characteristics of 60 adults chronic hair pullers. Am J Psychiatry 148 (1991): 365-370.

8. Vilela ACM, Azevedo BVP, Caixeta LF, et al. Trichotillomania associated with bipolar disorder and obsessive compulsive disorder: Pathoplasty or Comorbidity?. Int J Trichology 6 (2014): 36-37. 
9. American Psychiatric Association: Diagnostic and Statistical Manual of Mental Disorders, Fifth Edition. Arlington, VA, American Psychiatric Association (2013).

10. Caixeta L, Lopes DB. Trichotillomania in a dementia case. Dement Neuropsychol 5 (2011): 58-60.

Citation: Malalagama AS. A Pathoplastic Presentation of Trichotillomania in Severe Depression- A Case Report. Journal of Psychiatry and Psychiatric Disorders 2 (2018): 77-80.

(C) This article is an open access article distributed under the terms and conditions of the 